\title{
PARTICIPAÇÃO DO AGRONEGÓCIO NO PIB BRASILEIRO E SUA DEPENDÊNCIA DO SISTEMA RODOVIÁRIO PARA O ESCOAMENTO DA PRODUÇÃO
}

\author{
AGRIBUSINESS PARTICIPATION IN BRAZILIAN GDP AND ITS \\ DEPENDENCE ON THE ROAD SYSTEM TO TRANSPORT THE PRODUCTS
}

Recebido: 15/05/2018 - Aprovado: 29/6/2018 - Publicado: 30/7/2018

Processo de Avaliação: Double Blind Review

\author{
Hellen Gomes de Araújo ${ }^{1}$ \\ Graduação em Tecnologia em Gestão Financeira pela FATEC - Osasco \\ hellengomes1@gmail.com \\ Jonathan Samuel Jesus Pontes ${ }^{1}$ \\ Graduação em Tecnologia em Gestão Financeira pela FATEC - Osasco \\ jsjpontes@hotmail.com
}

\begin{abstract}
RESUMO: Um assunto muito abordado nos últimos quatro anos no Brasil é o fato de que o país está vivendo uma recessão e, a recuperação desse cenário poderia levar até uma década. Durante esse período, a atividade econômica foi afetada, refletindo no resultado do PIB, que registrou essas quedas de forma acentuada entre os anos de 2014 e 2016. Contudo, dentre os setores que compõem o PIB nacional, o setor do agronegócio permaneceu consistente e, apresentou na contramão dos demais setores, um crescimento da produção. Este trabalho tem o objetivo de trazer informações que sustentem a importância da produção agropecuária para a composição do resultado no país e, de que forma o setor sofre com a falta de investimentos no modal de transporte, aplicado majoritariamente para o escoamento dos produtos. Foram utilizados autores de influência na área econômica e dados de associações controladoras do setor agropecuário para basear o desenvolvimento do trabalho e demonstrar as origens da infraestrutura de transportes que hoje está aplicada no país. Aplicando a metodologia de estudo de caso, foi possível identificar os fatores político-econômicos que influenciaram, ao longo das últimas décadas, a forma como o Brasil desloca sua produção e, como isso interfere na competitividade dos produtos, principalmente, no que tange o custo que, posteriormente, determina o preço final.
\end{abstract}

Palavras-chave: PIB; agronegócio; transporte rodoviário.

\footnotetext{
${ }^{1}$ Autor para correspondência: Faculdade de Tecnologia do Estado de São Paulo, Rua Pedro Rissato, 30, Vila dos Remédios, Osasco - SP, Brasil - CEP 06296-220.
}

REMIPE- Revista de Micro e Pequenas Empresas e Empreendedorismo da Fatec Osasco V. $4 \mathrm{~N}^{\circ} 2$, jul.-dez. 2018. 
REMIPE

¿〕'Fatec

ABSTRACT: An issue that has been discussed a lot in the last four years in Brazil is the fact that the country is experiencing a recession and the recovery of this scenario might take about a decade. During this period, economic activity was affected, reflecting the $G D P$ result that registered a decrease between the years 2014 and 2016. However, among the sectors that make up the national GDP, the agribusiness remained consistent, and it has presented, against the other sectors, a growth of production. This paper aims to provide pieces of information that support the importance of agricultural production to constitute the Brazilian results and how the sector suffers from the lack of investments in terms of transportation mainly when applied to transport the products. Authors of influence in the economic field and data of agricultural sector controlling associations were used to base the development of this study and to demonstrate the origins of the transport infrastructure that nowadays is utilized in the country. Applying the case study methodology, it was possible to identify the political-economic factors that have been influencing, over the last decades, the way that Brazil transports its production and how this interferes in the competitiveness of the products, especially regarding cost, which subsequently determines the final price.

Keywords: GDP; agribusiness; road transportation.

\section{INTRODUÇÃO}

A partir do segundo semestre de 2014, o PIB demonstrava que reagiria mal ao período de instabilidade política, de escândalos envolvendo empresas estatais e ao auge da Operação Lava-Jato que estava se instalando no país. Um cenário de recessão parecia difícil de ser evitado e revertido em curto prazo.

Entre o segundo trimestre de 2014 e o terceiro trimestre de 2016, o PIB acumulava uma queda de $8,33 \%$ (OREIRO, 2017). Um outro fator que contribuiu para o início desse momento de crise, foi o início da Nova Matriz Econômica (NME), implantada entre os anos de 2011 e 2012. Nela, dentre outras práticas, foi possível observar uma política monetária de redução de taxas de juros, elevação de gastos e intervenção em preços (BARBOSA FILHO, 2017).

Dentre as áreas que compõem o PIB nacional, o agronegócio, mesmo sofrendo quedas consideráveis durante esse período, foi importante para conter uma queda ainda maior nos números. Segundo dados da Confederação da Agricultura e Pecuária do Brasil (CNA) , a participação do agronegócio contribuiu com 23,5\% para o PIB em 2017, a maior participação em 13 anos. Ainda segundo a CNA, o setor foi um dos responsáveis por conter a inflação em 2017 e, teve crescimento na oferta de empregos mais alto dos últimos 5 anos. As áreas de agricultura e produção de carne foram os 
REMIPE

Џ

únicos segmentos da economia que aumentaram a oferta de emprego naquele ano (ABAG, 2017).

Por sua grande extensão de terra e seu clima ameno, já é esperado do Brasil um excelente desempenho econômico do agronegócio. Um quinto de toda a produção do país é gerada nos campos: dos pequenos produtores até grandes empresas para abastecer o mercado interno e externo (CEPEA, 2016).

Mesmo com essa expressiva participação do setor para o desempenho econômico do país, os investimentos para infraestrutura, especialmente de transporte, não acompanham a demanda (ALGORTA; SALIB, 2003). Para Gilson Chequeto, CEO e diretor comercial da Transpobrasil, os principais problemas que o produtor precisa enfrentar são a falta de infraestrutura, a escassez de armazéns e o alto custo do frete, que é resultado de uma dependência do transporte rodoviário, o qual o país se dedicou em investir ao longo do século XX.

\section{REFERENCIAL TEÓRICO}

\subsection{PIB - CONCEITO}

Este conceito básico da economia acaba sendo pouco compreendido. Primeiramente, pois não se trata do resultado da economia de fato e, sim, do produto. São contabilizados os esforços da produção durante um ano. Por exemplo: na construção de um hospital é contabilizado o valor total que foi gasto na construção, ou seja, se for construído um belo hospital de luxo, o PIB será maior, entretanto, ele não será capaz de atender a necessidade da população como um todo. Por outro lado, se forem adotadas diversas medidas de saúde preventiva, que tornarão a população mais saudável, essas não afetarão a composição do PIB, mesmo que isso traga um maior bem-estar para os cidadãos (DOWBOR, 2014. p.58).

O PIB mensura o volume de atividades econômicas e não a efetividade positiva ou negativa que essas atividades trazem para a população de um país. Quando houve o naufrágio de um navio petroleiro da Exxon na costa do Alaska, foi preciso contratar 
REMIPE

ЏऍFatec

várias empresas para fazer a limpeza da área, o que causou um crescimento forte do PIB daquela região (DOWBOR, 2009).

Entretanto, ainda não foi possível desenvolver outro mecanismo que demonstre o desempenho da produção dos países. Mesmo cientes de suas deficiências na mensuração, os economistas de todo mundo utilizam o indicador enquanto buscam desenvolver indicadores alternativos, principalmente, um capaz de medir o bem-estar social da população (NÓBREGA, 2012).

$\mathrm{O}$ produto interno de uma economia representa o valor, a preços de mercado, dos bens e serviços realizados num país em certo período, normalmente, um ano. Esse produto leva em consideração apenas os bens e serviços finais produzidos e realizados pelas empresas no ambiente interno do país. Dessa forma, no cálculo do PIB de um país soma-se a produção de bens tangíveis, que compreendem desde veículos e máquinas até vestuário e alimentos e também os intangíveis, que englobam serviços de educação, médicos e domésticos. (ASSAF NETO, 2014, p.7).

Vale ressaltar exemplos de atividades que não entram no cálculo do PIB, são eles: bens intermediários; aqueles que foram utilizados na produção, uma vez que eles já foram contabilizados no preço total do bem; serviços não remunerados, isto é, a atividade de uma dona de casa, por exemplo; bens já existentes, ou seja, quando ocorre a venda e uma casa que já estava construída ou, até mesmo, a venda de um carro usado. A produção desses bens já foi contabilizada em anos anteriores (ASSAF NETO, 2014, p.7). 
REMIPE

ЏऍFatec

\section{2. ÚLTIMOS RESULTADOS DO PIB BRASILEIRO}

Gráfico 1 - Variação do PIB Brasileiro entre os anos de 2010 e 2017. Elaboração do autor:

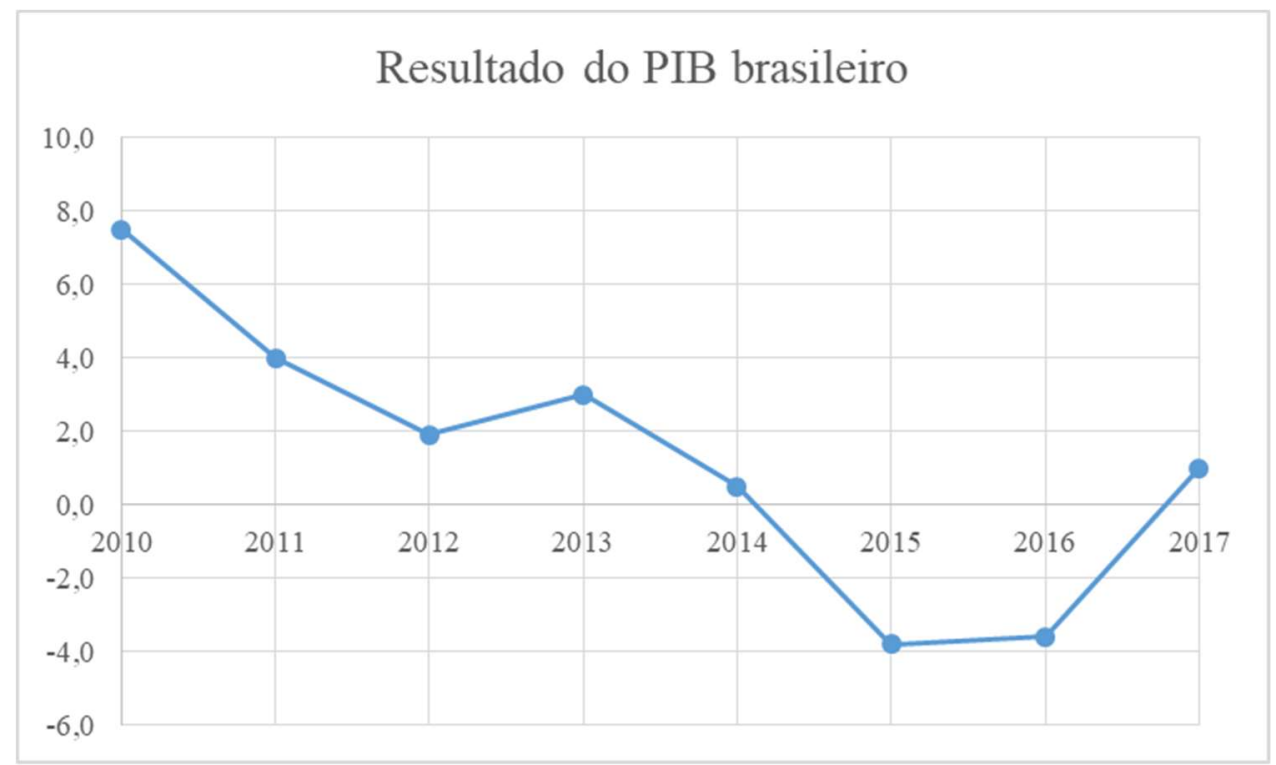

Fonte: Fundação Getúlio Vargas

Após um crescimento histórico no ano de 2010, como se pode observar no gráfico 1, chegando a 7,5\%, o Brasil começou uma sequência de intensa queda no resultado da sua produção interna. É possível atribuir essa queda ao encontro de dois grandes períodos. O primeiro se refere ao conjunto de políticas que não foram suficientes para sustentar o desenvolvimento econômico que vinha sendo apresentado até 2011. O segundo período é constituído por efeitos como aumento da taxa de juros, aumento do desemprego, a queda da renda, a contração do mercado de crédito e a redução dos investimentos públicos (PIRES, 2016).

Um outro fator determinante para o recuo nos investimentos de empresários e, consequentemente a queda no PIB, foi a forte retração dos investimentos no Grupo Petrobras em função dos efeitos combinados do alto grau de endividamento, da desvalorização do petróleo no mercado internacional e das implicações da Operação Lava-Jato (OREIRO, 2017). Todas essas incertezas colocaram o país em um momento delicado, fazendo os investidores adotarem uma postura que consiste em supor que a 
REMIPE

ЏऍFatec

situação atual irá persistir indefinidamente, a não ser que se tenha uma razão concreta para esperar uma mudança (KEYNES, 1936, p. 148).

\subsection{RESULTADO DO PIB DO AGRONEGÓCIO}

Durante os primeiros 20 anos do plano real (1994 - 2014), o agronegócio brasileiro registrou, em média, um crescimento de 3,9\%, número que seria suficiente para dobrar a produção, entretanto, é importante ressaltar que nesse período os preços sofreram uma tendência de baixa. Assim, só foi possível alcançar números expressivos devido a um aumento substancial na produção. Dessa forma, o setor precisou demonstrar sua resiliência suportando a volatilidade dos preços. Para isso, foi necessário um bom gerenciamento dos custos, visando redução (BARROS; CASTRO, 2017).

É importante ressaltar os setores que compõem o PIB do agronegócio. Na tabela 1, é possível verificar a participação média de cada uma destas áreas, considerando o período de 2010 a 2017:

Tabela 1 - Participação dos setores na composição do PIB do agronegócio brasileiro. Elaboração do autor:

\begin{tabular}{cc}
\hline Área & $\begin{array}{c}\text { Participação média nos } \\
\text { últimos } 7 \text { anos }\end{array}$ \\
\hline Serviços & $40 \%$ \\
Agroindústria & $30 \%$ \\
Agropecuária & $25 \%$ \\
Insumos & $5 \%$ \\
\hline
\end{tabular}

Fonte: Cepea/CNA, 2018

Com o gráfico 2, pode-se perceber a curva de aumento da produção que o agronegócio apresentou exatamente no mesmo período que o PIB geral do país apresentava quedas. Entre os anos de 2014 e 2016, acumulou um crescimento de 11,2\%, após ter se mantido praticamente estável entre 2013 e 2014 demonstrando a representatividade desse importante setor da economia (Cepea/CNA, 2018). 
Gráfico 2 - Evolução do PIB do Agronegócio brasileiro entre 2010 e 2017. Elaboração do autor:

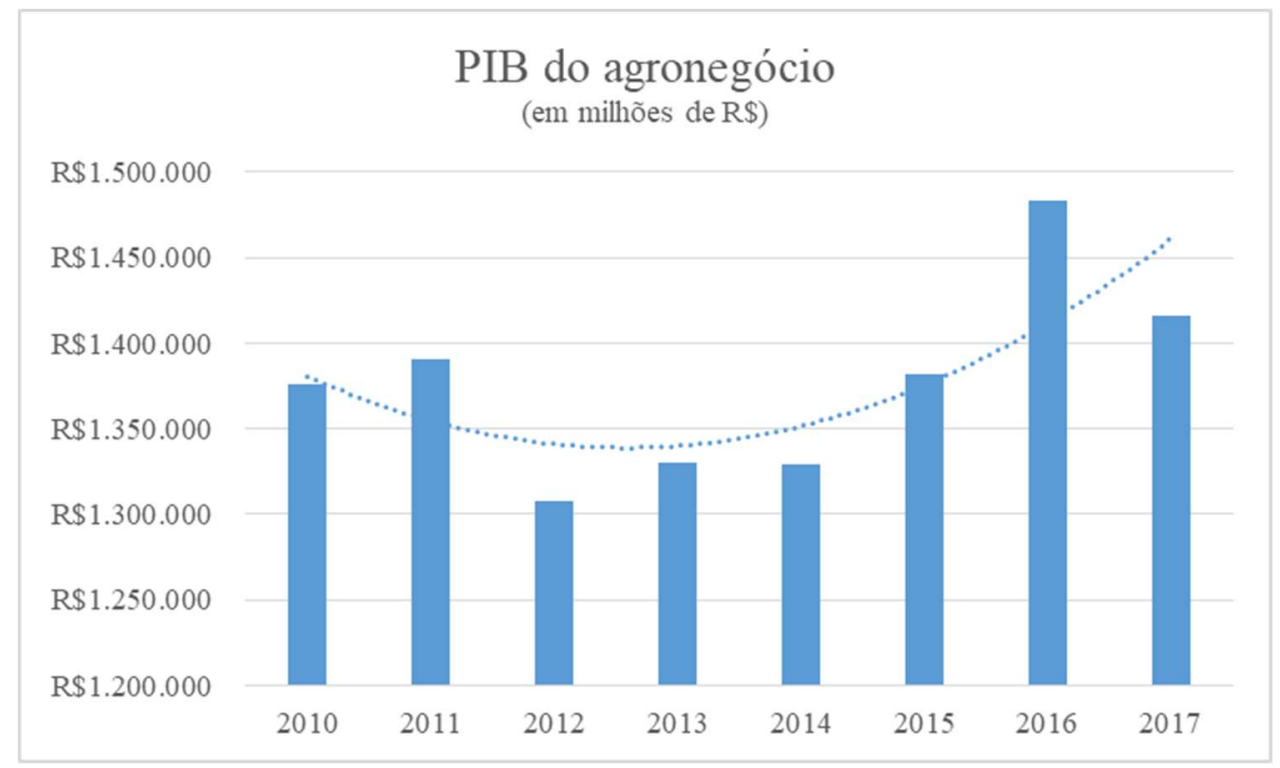

Fonte: Cepea/CNA, 2018

\section{METODOLOGIA}

Com o estudo de caso é possível uma investigação dos eventos da vida real na sua totalidade, tais como: ciclos de vida individuais, processos organizacionais e administrativos, mudanças que acontecem nas cidades, relações internacionais e amadurecimento de alguns setores. Ou seja, é utilizado devido ao desejo de se compreender fenômenos sociais complexos (YIN, 2001, p. 21).

A essência do estudo de caso é tentar esclarecer uma decisão ou conjunto de decisões, tentando esclarecer o motivo pelo qual elas foram tomadas, como foram implementadas e com quais resultados (SCHRAMM, 1971).

Dessa forma, foi aplicado ao longo deste artigo um estudo de caso sobre o cenário econômico no Brasil e como o agronegócio foi importante para a composição do PIB. Também foi abordado como ocorreu a implantação dos modais de transportes para o escoamento da produção desse importante setor e, como a escolha feita em 
REMIPE

meados do século XX reflete hoje como um fator determinante na competitividade dos produtos nacionais no exterior.

\section{ORIGEM DO ATUAL SISTEMA DE TRANSPORTE NACIONAL}

Com a justificativa de baixo custo de investimento para construção, se comparado com ferrovias e, também maior flexibilidade na locomoção, em meados do século XX, foi concedida prioridade para o desenvolvimento do modelo rodoviário para transportes no Brasil. Da mesma forma, a pressão das montadoras automobilísticas que começavam a se instalar no país foi determinante para a expansão de rodovias cortando o Brasil de norte a sul (ALGORTA; SALIB, 2003).

Em 1921, ocorre a inauguração da linha de montagem da FORD em São Paulo. Quatro anos mais tarde, em 1925, a General Motors (GM) inicia suas atividades. Em 1950, foi a vez da Volkswagen (VW) iniciar a produção do famoso "Fusca". Já, em 1962, a Toyota inicia sua linha de montagem em São Bernardo do Campo/SP e, em 1976, a Fiat inaugura sua fábrica em Betim/MG. Essas aberturas trouxeram expressivos valores de investimento para o Brasil, gerando empregos e movimentando a economia. De forma alguma, os governantes, sejam estaduais ou federais, poderiam barrar ou, até mesmo, deixar de investir em infraestrutura para que esse mercado crescesse.

Em 1930, o presidente Washington Luiz falou: “Governar é abrir estradas". Consequentemente, começou a implantação de toda infraestrutura não apenas de estradas, mas de todo o sistema de trânsito nacional. Já em 1939, iniciaram-se as obras para a construção da primeira estrada de longo percurso que ligava o Rio de Janeiro à Bahia. Essa estrada se tornou a primeira via efetiva de integração nacional. A rodovia Fernão Dias, ligando São Paulo à Belo Horizonte foi inaugurada em 1959 e, dois anos depois, a Regis Bittencourt é aberta para ligar Curitiba à São Paulo (ALBANO, 2006).

O Programa de Integração Nacional (PIN) foi implantado em 1970, pelo então presidente Emílio Garrastazu Médici. Dentre outras ações, estava a construção do que seria a maior rodovia do país, a "Transamazônica". Segundo o governo, isso iria diminuir a pobreza nos estados do Nordeste com a geração de postos de trabalho e a integração da Região Norte do país. Entretanto, o que se viu foi uma obra inacabada e que, nos dias atuais, voltou a ser engolida pela floresta (MOURA, 2016). 
REMIPE

ЏऍFatec

Mesmo com todo o investimento para o desenvolvimento da malha rodoviária, o que se pode observar é que mesmo após 80 anos desde o início da construção da primeira rodovia, o país ainda possui a maioria de suas rodovias não pavimentadas, segundo dados do relatório do Departamento Nacional de Infraestrutura de Transporte DNIT, 2013.

Gráfico 3 - Rede Rodoviária Nacional em 2013. Elaboração do autor:

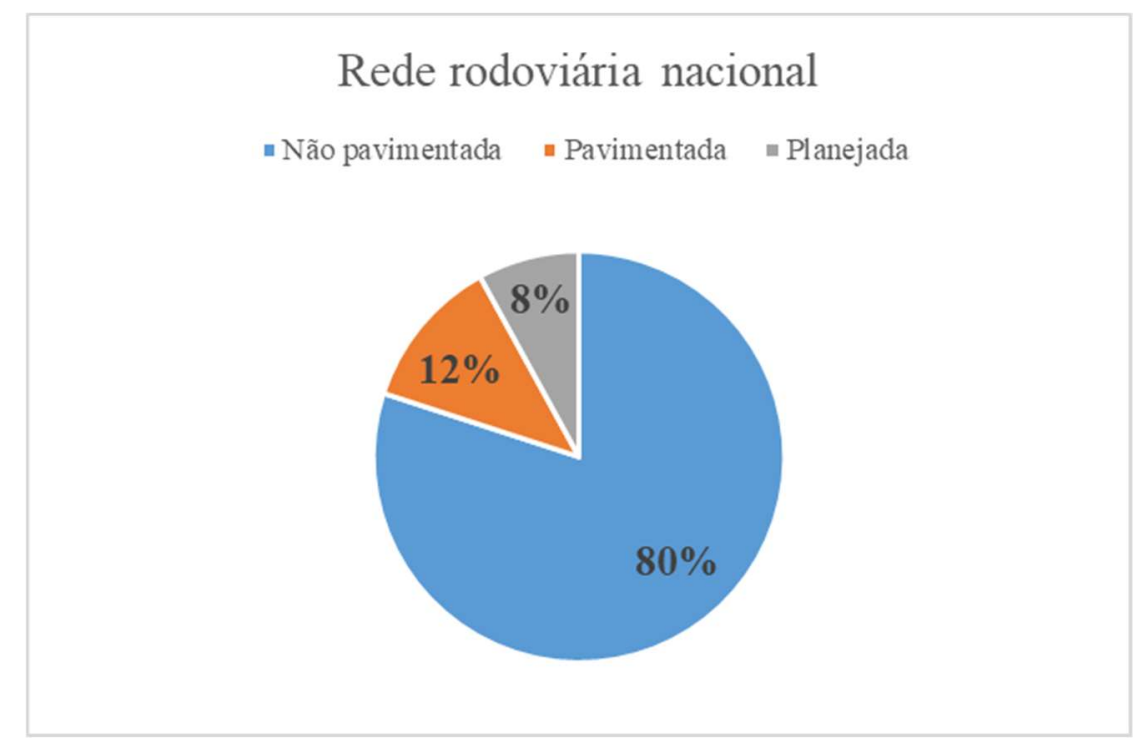

Fonte: DNIT, 2013.

\section{O PROBLEMA DO ESCOAMENTO DA PRODUÇÃO}

O sistema logístico é um fator determinante para a competitividade no mercado internacional. Se um país consegue desenvolver e disponibilizar para os seus produtores, um sistema eficiente, o preço desse produto no mercado mundial será mais competitivo, uma vez que teve um custo de escoamento mais otimizado (VIEITO, 2013).

O modal rodoviário, em uso majoritariamente no Brasil, é mais adequado para o transporte de curtas distâncias, trajetos que chegam a, no máximo, 300 quilômetros. Seria, então, utilizado no percurso entre a origem da produção até terminais ferroviários ou hidroviários, que fariam o transporte de longas distâncias, uma vez que tem capacidade maior de carga, trazendo assim uma redução de custos e perdas. 
REMIPE

ЏऍFatec

Existem dois tipos de custo que estão relacionados ao modal rodoviário, esses interferem diretamente na competitividade do preço internacional da soja, por exemplo. $\mathrm{O}$ primeiro está relacionado à inadequação desse meio às características do produto e às distâncias percorridas e, o segundo é a precariedade da malha rodoviária do país, em razão da escassez de recursos que se alastrou sobre políticas de infraestrutura, conforme foi possível verificar no gráfico 3 (CORREA; RAMOS, 2010).

\section{CONSIDERAÇÕES FINAIS}

Frente ao que foi apresentado, é possível perceber que a produção do agronegócio representa cerca de um quinto do PIB nacional. Mesmo durante o período de recessão iniciado em meados de 2014, o setor permaneceu forte e apresentou resultados crescentes, amenizando, em partes, a queda geral do PIB que desacelerou fortemente.

Entretanto, a lucratividade dos produtores acaba sendo afetada pela elevação dos custos trazidos, principalmente, pelo déficit de infraestrutura de modais de transporte no país. Percebe-se que o modelo mais recomendado dada as dimensões do país é o ferroviário, sendo capaz de transportar grandes cargas de maneira mais eficiente e rápida. Contudo, o modelo de deslocamento de produção que foi implantado ao longo do século XX no Brasil foi o rodoviário, influenciado pelos investimentos das grandes montadoras que se instalavam no país.

Além da escolha do modal de escoamento inadequado, o produtor enfrenta mais um problema grave para entregar sua produção: a má conservação dessas rodovias eleva o custo do frete, o que interfere na competitividade do preço da mercadoria. Esse transporte ainda sofre com o tempo maior gasto para ser entregue e na eminência da ocorrência de uma greve do setor caminhoneiro, o que levaria a perder boa parte de sua produção, ocasionando prejuízos de ordem financeira e de planejamento. 


\section{REFERÊNCIAS}

ABAG, Associação Brasileira do Agronegócio. Agronegócio contribui com 23,5\% do PIB em 2017. Disponível em: http://www.abag.com.br/sala_imprensa/interna/abagagronegocio-contribui-com-23-do-pib-1_ Acesso em: 11/06/2018

ALBANO, João Fortini. Evolução das Vias: Uma visão geral. Disponível em: http://www.producao.ufrgs.br/arquivos/disciplinas/420_03-evolucao_das_vias.pdf

ALGORTA, Juan Vicente Jose Plá; SALIB, Salimar. Infraestrutura de transporte e potencial agrícola no Brasil. Disponível em: https://revistas.fee.tche.br/index.php/indicadores/article/download/216/265

ASSAF NETO, Alexandre - Mercado Financeiro - 12 ed - São Paulo: Atlas, 2014

BARBOSA FILHO, Fernando de Holanda. A Crise econômica de 2014/2017. Disponível em: http://www.scielo.br/scielo.php?script=sci_arttext\&pid=S010340142017000100051

BARROS, Geraldo Sant'Ana de Camargo; CASTRO, Nicole Rennó. Produto Interno Bruto do agronegócio e a Crise Brasileira. Disponível em: https://www.researchgate.net/profile/Nicole_Castro2/publication/320616209_PRODUT O_INTERNO_BRUTO_DO_AGRONEGOCIO_E_A_CRISE_BRASILEIRĀ/links/59f 0abcc458515bfd07fa984/PRODUTO-INTERNO-BRUTO-DO-AGRONEGOCIO-E-ACRISE-BRASILEIRA.pdf

CEPEA - Centro de Estudos Avançados em Economia Aplicada. PIB do Agronegócio. Disponível em: https://edisciplinas.usp.br/pluginfile.php/4211393/mod_resource/content/1/pbmacro.pdf

CEPEA - Centro de Estudos Avançados em Economia Aplicada. PIB do Agronegócio Brasileiro. Disponível em: https:/www.cepea.esalq.usp.br/br/pib-do-agronegociobrasileiro.aspx

CORREA, Vivian Helena Capacle; RAMOS, Pedro. A precariedade do transporte rodoviário brasileiro para o escoamento da produção de soja do Centro-oeste: Situação e perspectivas. Revista de economia e sociologia rural vol.48 $\mathrm{n}^{\circ} 2$ Brasília Apr/June 2010. Disponível em: http://www.scielo.br/scielo.php?pid=S0103$20032010000200009 \&$ script $=$ sci_arttext\&tlng=es

DNIT - Departamento Nacional de Infraestrutura de Transportes. Relatório dos levantamentos funcionais das rodovias federais - 2013. Disponível em: http://www.dnit.gov.br/download/planejamento-e-pesquisa/planejamento/evolucao-damalha-rodoviaria/relatorio-sgp-2012-2013-brasil.pdf 
DOWBOR, Ladislau. O Debate sobre o PIB: Estamos fazendo a conta errada. Disponível em: http://tinyurl.com/qxxlzqt .

. Os mecanismos econômicos. Disponível em: http://dowbor.org/blog/wpcontent/uploads/2012/06/14-Como-Funciona-a-Economia.doc

KEYNES, J. M. The general theory of employment, interest and money. London: Macmillan, 1936.

MOURA, Jose Elierson de Souza. A esperança de um, o otimismo de todos: A cidade de Picos e a rodovia Transamazônica percorrida/escrita pelo jornalista Rangel Cavalcante em 1970 . 1 Disponível http://www.periodicos.ufpb.br/ojs/index.php/tematica/article/view/30204/15966

NOBREGA, Maílson da. A proposta de Dilma é válida, mas o que mede para valer é o PIB. Disponível em: http://mailsondanobrega.com.br/blog/proposta-de-dilma-evalida-mas-o-que-mede-para-valer-e-o-pib/

OREIRO, Jose Luiz. A grande recessão brasileira: diagnóstico e uma agenda de política econômica. Disponível em http://www.scielo.br/pdf/ea/v31n89/0103-4014-ea31-89-0075.pdf

PIRES, Manoel C. C. Política economia e estabilização: uma breve análise da recessão brasileira. Disponível em: http://www.braziliankeynesianreview.org/index.php/BKR/article/view/87/68

SCHRAMM, W. - Notes on case studies of instructional mediaprojects. Working paper, the Academy for Educational Development - 1 $^{\mathrm{a}}$ ed - Washington: 1971

TRANSPOBRASIL. Os gargalos no escoamento da produção agrícola. Disponível em: $\quad$ http://www.transpobrasil.com.br/2017/03/29/os-gargalos-no-escoamento-daproducao-agricola/

VIEITO, Manuel Antonio Deus. Planejamento e Logística no agronegócio. Dissertação de MBA em Gestão do Agronegócio - UFPR - Universidade Federal do Paraná. Disponível em: https://acervodigital.ufpr.br/bitstream/handle/1884/49623/R\%20-\%20E\%20$\% 20$ MANUEL\%20ANTONIO\%20VIEITO\%20DEUS.pdf?sequence=1

YIN, Robert K. - Estudo de caso. Planejamento e Métodos $-2^{\text {a }}$ ed - Porto Alegre: Bookman, 2001 